\title{
Expression of the exoY gene, required for exopolysaccharide synthesis in Agrobacterium, is activated by the regulatory ros gene
}

\author{
Anne Tiburtius, Nicola G. de Luca, Haitham Hussain \\ and Andrew W. B. Johnston

\begin{abstract}
Author for correspondence: Andrew W. B. Johnston. Tel: +441603 592264. Fax: +441603592250
e-mail: a,johnston(a) uea,ac,uk
\end{abstract}

School of Biological Sciences, University of East Anglia, Norwich NR4 7TJ, UK
Some mutants of Agrobacterium radiobacter, defective in exopolysaccharide synthesis, were phenotypically complemented by two different regions of cloned chromosomal DNA. One of these had been shown to contain a gene termed ros, a novel class of transcriptional regulator. The other contains a gene termed exo $Y$ which encodes a glycosyltransferase that is involved in one of the early steps in exopolysaccharide synthesis. Mutations in ros reduced the expression of exo $Y$ and a model to account for the complementation of certain exo alleles by both ros and exo $Y$ is presented. TnphoA insertions into exo $Y$ which expressed alkaline phosphatase activity were isolated and mapped, confirming the membrane location of the exor gene product. Some of these mutations were dominant, causing merodiploids to be non-mucoid. exoY is linked to two genes, one encoding an $\omega$-aminotransferase and the other encoding an aldehyde dehydrogenase.

Keywords: Agrobacterim, dominant exo mutation, exopolysaccharide, gene regulation, ros

\section{INTRODUCTION}

The bacteria Agrobacterium and Rhizobium interact with higher plants, several of the former inducing tumours, and members of the latter forming nitrogen-fixing root nodules on legumes. Like many other Gram-negative bacteria, they make high-molecular-mass acidic exopolysaccharide (EPS) (reviewed by Leigh \& Coplin, 1992, and Leigh \& Walker, 1994). The rhizobial genes encoding these molecules have been studied in most detail in Rhizobium meliloti (now known as Sinorbizobium meliloti) the symbiont of alfalfa. By sequencing and genetic analyses, 22 exo genes, needed for the synthesis of the normal succinoglycan of $R$. meliloti, were identified and biochemical functions were ascribed to many of them (Reuber \& Walker, 1993; Becker et al., 1993a-c; Buendia et al., 1991). In R. meliloti, nearly all the exo genes are contiguously arranged on a large indigenous plasmid (Finan et al., 1986), and their transcription is controlled by two negatively acting transcriptional genes, exoS and

Abbreviations: AP, alkaline phosphatase; EPS, exopolysaccharide. The GenBank/EMBL accession number for the sequence reported in this paper is $\times 95394$
exoR, which are located on the Rbizobium chromosome (Doherty et al., 1988; Reed et al., 1991b).

Strains of Agrobacterium make an EPS that is chemically similar to that of R. meliloti (Sutherland, 1985) but the genetics of its production have been less well studied. Cangelosi et al. (1987) isolated several exo mutants of $A$. tumefaciens and cloned the corresponding DNA. Several of these were complemented by the corresponding R. melilati genes, but some were not. Aird et al. (1991) also isolated non-mucoid exo mutants of a strain of $A$. radiobacter (which lacks any tumour-inducing plasmid). Analysis of these mutants revealed features that distinguished them from those of $R$. meliloti.

Firstly, the mutations were scattered in different regions of the genome; i.e. different mutants were complemented only by certain non-overlapping cosmids from an $A$. radiobacter gene bank - there were at least five such nonovetlapping cosmid contigs. Secondly, despite the chemical similarity of the EPSs of the two genera, only mutations in exoB of $\mathrm{R}$. meliloti were complemented by $A$. radiobacter exo genes. Some exo mutants were 'conditional', being EPS ${ }^{+}$on medium containing glucose or glycerol but EPS with dicarboxylic acids as sole C source. An unexplained observation was that certain exo 
mutants, which included some of the conditional ones, accumulated protoporphyrin IX, the immediate precursor of haem. Lastly, it was found that certain mutations, again including the conditional ones, were complemented by two non-overlapping cosmids, pBIO11 and pBIO21, which had no cloned DNA in common. To explain this last observation, Aird et al. (1991) suggested that such mutations were in a positively acting regulatory gene so that they could be complemented not only by cloning that gene itself but also by cloning, in a multi-copy vector, the 'target' structural gene that was activated by this proposed regulator. Thus, the target gene might become 'deregulated' and so no longer require activation of its transcription.

Some support for this idea came from Brightwell et al. (1995) who showed that the gene in one of the cosmids (pBIO11) which complemented these alleles corresponded, both in function and in sequence, to a known transcriptional regulator, termed ros, (rough outer surface) in A. tumefaciens (Close et al., 1985; Cooley et al., 1991) which had the following properties. It represses transcription of itself and of two other loci, virC and virD, which are involved in tumour induction. It encodes a $14.5 \mathrm{kDa}$ protein that binds to sequences (ros boxes) preceding genes that it regulates (D'Souza-Alt et al., 1993). Brightwell et al. (1995) showed that this repressive activity was augmented by the presence of iron and glucose in the growth media. The ros gene of $A$. radiobacter and $A$. tumefaciens complemented both the EPS and the porphyrin defects of the relevant $A$. radiobacter mutants (Brightwell et al., 1995). Mutations that deleted the $3^{\prime}$ end of ros had a dominant mutant phenotype; when plasmids containing such cloned mutants were present in wild-type $A$. radiobacter or Rbizobium, the transconjugants were non-mucoid. If, as is normal with DNA-binding proteins, Ros is multimeric, maybe the presence of a truncated version of mutant ros results in the formation of an inactive protein complex (Brightwell et al., 1995).

Keller et al. (1995) characterized a gene, muR, of $\mathrm{R}$. meliloti with a similar sequence to ros. The muc $\mathrm{R}$ mutants did not make the normal polysaccharide (EPS I) but made a different polymer, EPS II, which is not made by wildtype R. meliloti (Glazebrook \& Walker, 1989). mucR repressed the $\exp$ genes that encode EPS II, but had no effect on transcription of the exo genes that encode EPS I, although mucR mutants made less EPS I than did the wildtype.

The second cosmid, with cloned $A$. radiobacter DNA that complemented those exo mutants that were also complemented by ros, was termed pBIO21. Aird et al. (1991) localized the exo DNA to a $4.5 \mathrm{~kb}$ region of $\mathrm{pBIO} 21$ and showed that some mutations in this DNA not only abolished its ability to complement the mutants, but were 'dominant', causing wild-type strains of Agrobacterium and also of Rbizobium to be non-mucoid when such mutant plasmids were present. Certain exo-pho $A$ fusions in pBIO21 expressed alkaline phosphatase (AP), indicating that the product of the exo gene(s) is associated with the bacterial periplasm or membrane(s), something that has been established for several exo genes (Latchford et al., 1990; Long et al., 1988; Reuber et al., 1991), and is consistent with the hydrophobicity pattern of ExoY and homologous proteins (e.g. Borthakur et al., 1988). We therefore speculated (Aird et al., 1991) that the exo gene(s) in $\mathrm{pBIO} 21$ included one or more of the targets for the regulatory gene that was later identified as ros. Here, we present a molecular analysis of this region and identify the relevant exo gene in $\mathrm{pBIO} 21$ and its relation to ros and other neighbouring genes.

\section{METHODS}

Strains and plasmids. Bacterial strains and plasmids used in this work are listed in Table 1.

Media, general growth conditions and in vivo genetic manipulations. For Agrobacterium, these were as described by Aird et al. (1991). In triparental matings, pRK2013 (Figurski \& Helinski, 1979) was used as the helper plasmid to mobilize recombinant plasmids based on PLAFR1 or PMP220 into Rbizobium or Agrobacterium. Transposon mutagenesis of $\mathrm{pBIO} 60$ was done as described for the mutagenesis of $\mathrm{pBIO} 21$ by Aird et al. (1991).

AP assay. Quantitative AP assays were performed as described by Brickman \& Beckwith (1975), except that activities were expressed as a function of cellular protein concentration that was determined by the Bicinchoninic Acid Protein Assay Kit (Sigma) according to the manufacturers' instructions. Cells to be assayed were harvested at mid-exponential phase, thus minimizing the risk of spurious AP activity when the enzyme was present in the cytoplasm of cells that were in stationary phase (see Derman \& Beckwith, 1995).

DNA manipulation. For routine analysis and isolation of DNA (transformation, restriction mapping, etc.), experiments were done using the protocols (or minor variants thereof) described by Sambrook et al. (1989). DNA was sonicated, fractionated into fragments approximately $400 \mathrm{bp}$ in length, and the ends were filled in and ligated to appropriate vectors as described by Rossen et al. (1984). Fluorescently labelled oligonucleotides were synthesized by Richard James on a Bioresearch Cyclone oligonucleotide synthesizer (University of East Anglia, Norwich) according to the manufacturers' instructions, and the PCR products were prepared on an LEP Scientific cycler. DNA was sequenced using the dideoxy chain-termination method and gels were run on an ALF automated sequencer (Pharmacia) according to the manufacturers' instructions.

Sequences were assembled using the DNAStar and Gene Jockey programs, and sequence comparisons were done using BLASTX and FASTN searches of data bases.

\section{RESULTS}

\section{Sequence of the exoY region of A. radiobacter}

The relevant exo region of cosmid pBIO21 region had been localized to a $4.5 \mathrm{~kb}$ Eco RI-BamHI fragment that, when cloned in the wide-host-range plasmid pMP220 to form pBIO60, corrected all the mutants that were complemented by the original cosmid. Further, all the transposon insertions that abolished the ability of pBIO21 to complement the exo mutants were located in the same fragment (Aird et al., 1991).

This cloned DNA was sonicated and the resulting small fragments were cloned into pUC18 for sequencing of both 
Table 1. Bacterial strains and plasmids

\begin{tabular}{|c|c|c|}
\hline Strain/plasmid & Characteristics & Reference/source \\
\hline \multicolumn{3}{|l|}{ E. coli } \\
\hline 803 & $\mathrm{Met}^{-}$, used as a recipient in routine transformations & Wood (1966) \\
\hline JM101 & $\mathrm{F}^{-}$traD36 pro $A^{+}$pro $B^{+}$lac ${ }^{9}$ lac $Z \Delta M 15 \sup E$ thi $\Delta($ lac-pro $A B)$ & Messing et al. (1983) \\
\hline \multicolumn{3}{|l|}{ A. radiobacter } \\
\hline T1305 & Wild-type; Str ${ }^{\mathrm{R}}$ & Aird et al. (1991) \\
\hline Exo 51.1 & $\mathrm{Exo}^{-}$, complemented by $\mathrm{pBIO} 11$ and $\mathrm{pBIO} 21$ & Aird et al. (1991) \\
\hline Exo 53.1 & Exo $^{-}$, complemented by $\mathrm{pBIO} 11$ and $\mathrm{pBIO} 21$ & Aird et al. (1991) \\
\hline Exo 63 & $\mathrm{Exo}^{-}$, complemented by $\mathrm{pBIO} 11$ and $\mathrm{pBIO} 21$ & Aird et al. (1991) \\
\hline Exo 66.1 & Exo-, complemented by $\mathrm{pBIO} 11$ and $\mathrm{pBIO} 21$ & Aird et al. (1991) \\
\hline Exo 70.1 & Exo $^{-}$, complemented by pBIO21 only & Aird et al. (1991) \\
\hline Exo 73.1 & Exo-, complemented by pBIO21 only & Aird et al. (1991) \\
\hline Exo 81 & $\mathrm{Exo}^{-}$, complemented by $\mathrm{pBIO} 11$ and $\mathrm{pBIO} 21$ & Aird et al. (1991) \\
\hline \multicolumn{3}{|l|}{ Plasmids } \\
\hline pUC18 & $\mathrm{Amp}^{\mathrm{R}}$ & Vieira \& Messing (1984) \\
\hline pRK2013 & $\mathrm{Kan}^{\mathrm{R}}$, used for mobilizing P1-group plasmids & Figurski \& Helinski (1979) \\
\hline PLAFR1 & Tet ${ }^{R}$, wide-host-range P-group cloning vector & Friedman et al. (1982) \\
\hline pMP220 & $\mathrm{Tet}^{\mathrm{R}}$, lac $Z$, wide-host-range $\mathrm{P}$-group cloning vector & Spaink et al. (1987) \\
\hline $\mathrm{pBIO} 21$ & pLAFR1-based cosmid, contains $A$. radiobacter exo $Y$ & Aird et al. (1991) \\
\hline pBIO60 & $4.5 \mathrm{~kb} E_{i} i \mathrm{RI}-\mathrm{Bam}_{\mathrm{HI}}$ fragment in pMP220, contains $e \times 0 \mathrm{Y}$ & Aird et al. (1991) \\
\hline pBIO903 & $3.1 \mathrm{~kb}$ SmaI-deletant of pBIOG0 & This work \\
\hline $\mathrm{pBIO} 912$ & $1.6 \mathrm{~kb} P s t \mathrm{I}-B_{a m} \mathrm{HI}$ fragment in pMP220, contains $e \times 0 Y$ & This work \\
\hline pBIO917 & $\begin{array}{l}1.2 \mathrm{~kb} S \mathrm{maI} \text { fragment in pMP220, exoY not intact, contains } 700 \mathrm{bp} \text { upstream } \\
\text { of exoY }\end{array}$ & This work \\
\hline pB1O918 & $\begin{array}{l}1.1 \mathrm{~kb} N d e \mathrm{I}-\mathrm{BamHI} \text { fragment in pMP220, contains intact exoY and } 300 \mathrm{bp} \\
\text { upstream of exoY }\end{array}$ & This work \\
\hline $\mathrm{pBIO} 2$ & Tnpbo $A$ pBIO21 mutant containing the dominant exoY1:: Tnpbo $A$ allele & This work \\
\hline pBIO69 & Tnpbo $A$ pBIO21 mutant containing the exo Y2::Tnpbo $A$ allele & This work \\
\hline $\mathrm{pBIO} 72$ & Tnpbo $A$ pBIO21 mutant containing the exoY3:: Tnpho $A$ allele & This work \\
\hline
\end{tabular}

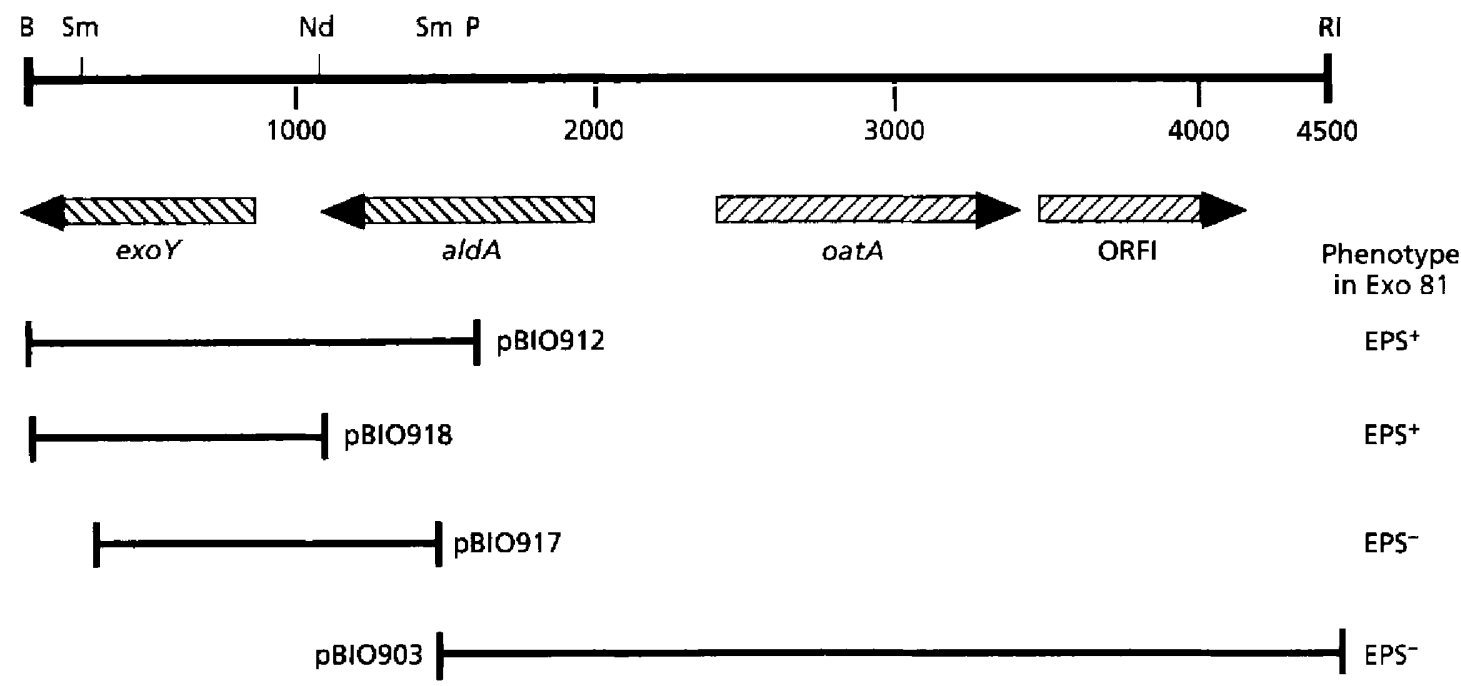

Fig. 1. Diagrammatic representation of the exor region of $A$. radiobacter. Dimensions and orientations of the four genes referred to in the text are shown as hatched boxes. The sizes of the fragments cloned into pMP220 and the names of the resultant plasmids are presented; cloning sites used were BamHI (B), Smal (Sm), Ndel (Nd), Pstl (P) and EcoRI (RI). The ability of the plasmids to complement the EPS-defect of mutant Exo 81 is indicated. 


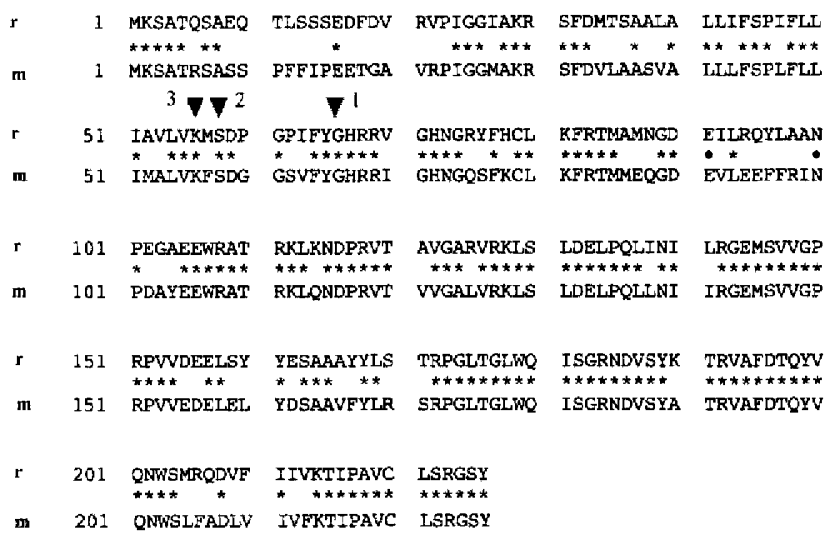

Fig. 2. Sequence of the deduced ExoY product of $A$. radiobacter (r), compared with the corresponding gene in $R$. meliloti $(\mathrm{m})$. Identical amino acid residues are asterisked. The sites of the three exoY::TnphoA insertions are shown as triangles; the exor alleles in each mutant are indicated.

forward and reverse strands. Once about $80 \%$ of the sequence had been obtained, the gaps wete filled in either by primer walking or by making specific subclones designed from restriction sites that had been revealed from the sequence. The $4.5 \mathrm{~kb}$ sequence was searched for the presence of ORFs and one obviously relevant gene was apparent (Fig. 1).

\section{Identification of exoY}

The deduced protein product of an ORF that extended from position 737 to 61 (Fig. 2) had a striking resemblance in sequence, size and hydrophobicity (Fig. 3) to that of several other genes that had been shown to be involved in EPS synthesis in various bacteria (Borthakur $e$ t al., 1988; Reuber \& Walker, 1993; Vanderslice et al., 1989; Jiang et al., 1991). These included the products of the exoY gene of R. meliloti $(82 \%$ amino acid identity), pss $A$ of $\mathrm{R}$. leguminosarum $(81 \%), r f b P$ of Salmonella $(70 \%)$, gumD of Xanthomonas $(71 \%)$ and $c p s D$ (Rubens et al., 1993) of Streptococcus $(81 \%)$. The succinoglycan of Rbizobium and, presumably, Agrobacterium is synthesized from UDP on membrane-bound lipid carriers, as is the case for other Gram-negative bacteria. The exo $Y, r f b P$ and gumD genes are believed to encode a glycosyltransferase that adds the first sugar to these isoprenoid carriers (see Reuber \& Walker, 1993). Despite the sequence similarities, neither the cloned $p s s A$ gene of $\mathrm{R}$. leguminosarum, nor the related exoY of R. meliloti, complemented the EPS ${ }^{-}$defect of any of the $A$. radiobacter mutants that were restored by $\mathrm{pBIO} 60$, nor did $\mathrm{pBIO} 60$ complement $p s s A$ mutants of $\mathrm{R}$. leguminosarum (Aird et al., 1991). It has been noted that the ExoY (PssA) proteins of Rbizobium are both located in the bacterial membrane (see Reuber \& Walker, 1993; Latchford et al., 1990).

To determine if exo $Y$ of $A$. radiobacter was sufficient to complement the mutants that were complemented by the intact pBIO60, various subclones of pBIO60 were made, the cloned DNA being inserted into the wide-host-range vector pMP220. The resulting plasmids were mobilized into the exo mutants listed in Table 1 and the transconjugants were examined for their ability to restore EPS synthesis on media with glucose or succinate as sole C source. All plasmids that contained the intact exo $Y$ gene restored EPS synthesis to all the mutants on both $\mathrm{C}$ sources, the smallest such plasmid being pBIO918, which contained only exoY (Fig. 1). These exo mutants included

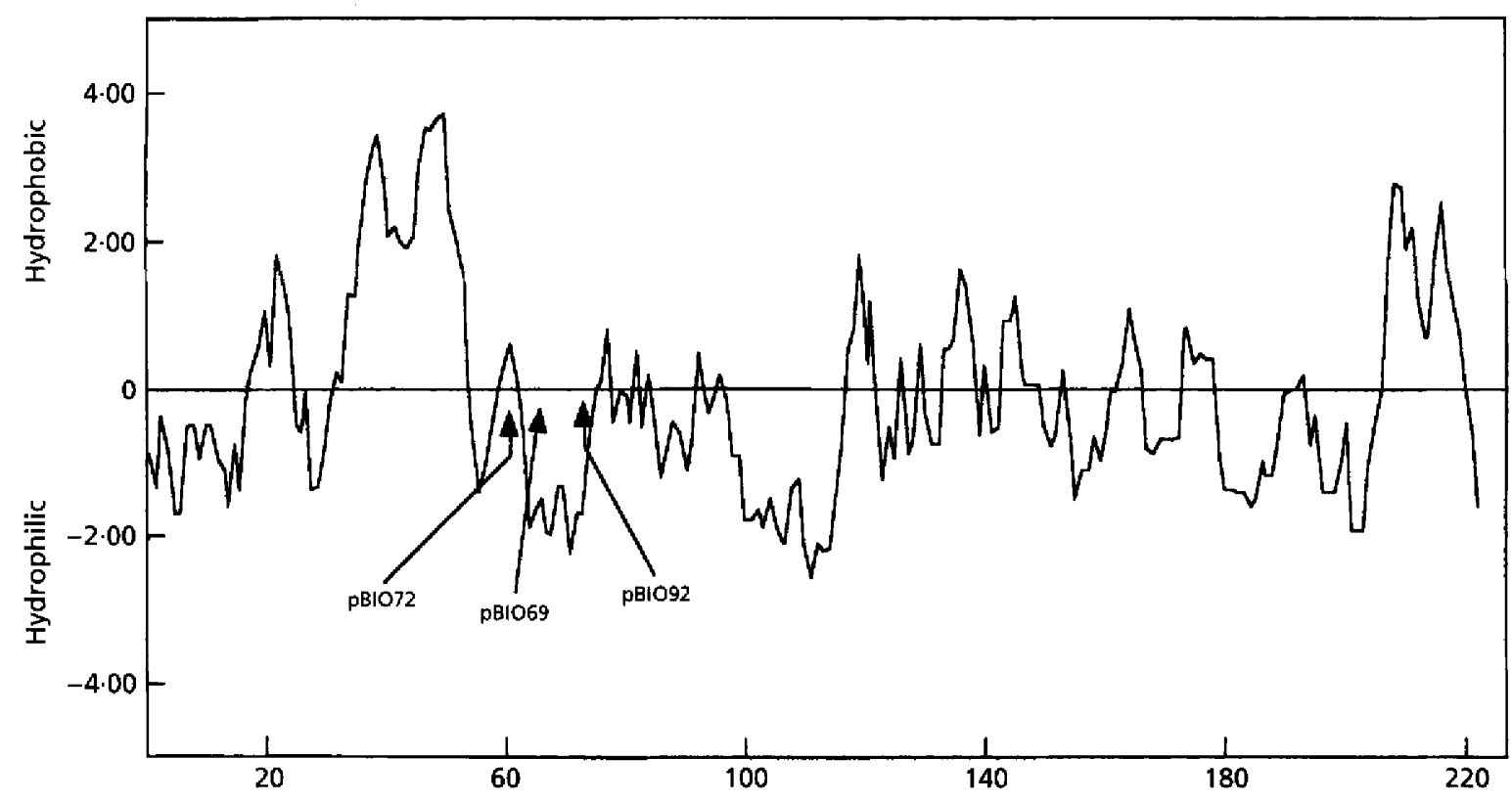

Fig. 3. Hydrophobicity profile of the product of exoY showing the sites of the TnphoA insertions. The sequence was analysed using the Kyte \& Doolittle (1982) algorithm with a window of 12 amino acids. 
Table 2. Effect of ros on expression of exoY-phoA

\begin{tabular}{|ccccc|}
\hline Plasmid & \multicolumn{3}{c|}{ AP activities* in background strain: } \\
\cline { 2 - 5 } & T1305 & Exo 81 & Exo 53.1 & Exo 66.1 \\
\hline pBIO21 & $22 \cdot 1 \pm 1 \cdot 9$ & $20 \cdot 3 \pm 2 \cdot 6$ & $11 \cdot 6 \pm 6 \cdot 8$ & $18 \cdot 3 \pm 6 \cdot 5$ \\
pBIO72 & $264 \cdot 3 \pm 34 \cdot 4$ & $63 \cdot 4 \pm 18 \cdot 7$ & $\begin{array}{c}75 \cdot 9 \pm 17 \cdot 9 \\
100 \cdot 4 \pm 16 \cdot 7\end{array}$ & $145 \cdot 4 \pm 64 \cdot 1$ \\
pBIO92 & $365 \cdot 2 \pm 30 \cdot 7$ & $40 \cdot 3 \pm 10 \cdot 5$ & $189 \cdot 5 \pm 70 \cdot 1$ \\
\hline
\end{tabular}

* AP activities are expressed as a function of cellular protein concentration.

some (Exo 81, Exo 66.1, Exo 53.1 and Exo 63) which were complemented by both exoY and ros, and others (Exo 70.1 and Exo 73.1) which were complemented only by exoY. In contrast, none of the new constructs, nor pBIO60 itself, complemented the porphyrin over-production of the mutants Exo 53.1 and Exo 81. We conclude that exoY is indeed sufficient to complement all the exo mutants complemented by the original cosmid pBIO21 for EPS synthesis. This was substantiated by mapping the mutant derivatives of cosmid $\mathrm{pBIO} 21$ which no longer complemented the exo mutants.

\section{Mapping of exoY::phoA mutations}

Following mutagenesis of $\mathrm{pBIO} 21$ with Tnpho A (Manoil \& Beckwith, 1985), three mutant derivatives of $\mathrm{pBIO} 21$, termed pBIO69, pBIO72 and pBIO92, which no longer complemented any of the exo mutants that wete complemented by pBIO21, were isolated (Aird et al., 1991). These three fusions expressed AP activity in free-living cells (Aird et al., 1991, and below). This suggested that the AP part of the fusion was localized in the periplasm aithough occasional anomalous results with pho $A$ fusions have been reported when fusions are at the $\mathrm{N}$-terminus of the protein (Prinz \& Beckwith, 1994). However, in plasmids pBIO69, pBIO72 and pBIO92 this is not the case (see below). Interestingly, one of these alleles, exoY1::Tnpbo $A$ was dominant; the mutant plasmid, pBIO92, which contained this allele caused both $R$. leguminosarum and $A$. radiobacter wild-type strains to become non-mucoid on media containing either glucose or succinate as $C$ source. In contrast, wild-type strains containing $\mathrm{pBIO} 69$ or $\mathrm{pBIO} 72$ (containing the $e \times 0 Y 2$ and the exo $\mathrm{Y}^{3}$ alleles, respectively) were fully mucoid. All these mutant plasmids expressed high levels of AP activity in Agrobacterium and in R. leguminosarum (see Table 2). Since the $p b o A$ gene in Tnpbo $A$ lacks the signal sequence that guides AP to the periplasm (the subcellular compartment in which the enzyme has activity), this means that the AP part of the fusion protein must be in the periplasm, consistent with the proposed inner membrane location of exoY (Latchford et al., 1991; Reuber \& Walker, 1993).

Approximate restriction mapping located these insertions to the $4.5 \mathrm{~kb}$ EcoRI-BamHI fragment of pBIO21 that had been sequenced and to that part of the DNA in which $e x o Y$ had been found. Further, in all three cases, pbo $A$ in the transposon was in the same orientation as exoY. To map the insertions precisely, a novel $B a m \mathrm{HI}$ fragment that had been created due to the insertion of $\operatorname{Tn} p h o A$ was cloned into plasmid $\mathrm{PUC18}$; this cloned fragment contained part of the transposon plus the Agrobacterium DNA that lay immediately upstream of the $p b o A$, i.e. which extended to the next genomic BamHI site.

Using a primer that corresponded to the $5^{\prime}$ region of the pho $A$ gene, the junctions of the insertions into exo $Y$ were determined and are shown in Figs 2 and 3. The three inserts were close to each other, all being towards the $5^{\prime}$ coding region of exoY. In fact, the sites of the insertions were no more than $33 \mathrm{bp}$ apart, the dominant allele, exoY1:: Tnpbo $A$, being the $3^{\prime}$-most of the three.

\section{Why are some exoY mutants dominant?}

The finding that at least one exo $Y$ mutant of $A$. radiobacter was dominant is reminiscent of a similar situation in Rhizobium. In R. meliloti, exoY is transcribed divergently from another gene, exoX, which also encodes a membrane-bound protein. When a recombinant plasmid containing both genes is present in a strain of wild-type $R$. meliloti, the bacteria appear normal. However, mutant plasmid-derivatives carrying mutations in exo $Y$ cause a non-mucoid phenotype in wild-type strains. This is due to a surfeit of the ExoX protein relative to ExoY, and is thought to disrupt the normal interaction between these two proteins in the inner membrane, which somehow results in the impairment of EPS synthesis (Reed $e t$ al., 1991a). A similar situation was described by Gray $e t$ al. (1990) for Rbizobium strain NGR234. An analogous though slightly different phenomenon has also been described in a strain of R. Leguminosarum biovar phaseoli (Borthakur et al., 1985; Borthakur \& Johnston, 1987). Here, a gene termed psi $A$, when cloned, also caused wildtype Rbizobium to become non-mucoid. The deduced products of psi $A$ and exoX have very similar sizes, both are located in the inner membrane and their hydrophobicity plots are almost superimposable (sec Gray et al., 1990); strikingly, though, the two proteins have extremely limited identity at the amino acid sequence level.

Thus, it seemed possible that the dominant effect of the exo Y1:: Tnpbo $A$ mutation in $\mathrm{pBIO} 2$ could be due to the presence of an $\operatorname{exaX} / p$ si $A$-like gene in the parental cosmid $\mathrm{pBIO} 21$. To test if this proposed gene was in the DNA sequences here, plasmid pBIO60 which contains the 
region of DNA sequenced here, was mutagenized with In $p$ bo $A$, and mutant derivatives that caused Rbizobium and Agrobacterium to be non-mucoid were isolated. Mapping the sites of these insertions showed that the Tnpbo As had inserted towards the 5' end of exoY. Thus, if the dominant effects were due to the inhibitory effects of an exoX-like gene being revealed when exo $Y$ was mutated, this hypothetical gene must be located in the cloned DNA in pBIO60. However, this was shown not to be the case in two different ways.

Firstly, the sequenced region was scanned for sequences with similarity to ExoX and PsiA; none was found. Since PsiA and ExoX themselves have little sequence identity to each other (Gray et al., 1990) but have similar sizes $(10 \mathrm{kDa})$ and near-identical and extremely characteristic hydrophobicity plots (a very hydrophobic $\mathrm{N}$-terminal half and an extremely hydrophilic C-terminal half), every ORF in the sequenced region was examined for any that had the same similar features; again, none was found.

If, nevertheless, there is a gene in $\mathrm{pBIO} 60$ which has the same properties as exo $X$, it should have been possible to identify it by subcloning regions of this plasmid which lack the intact exoY gene. Therefore, plasmids containing regions spanning the whole of the cloned DNA in pBIO60, but which lacked intact $e x 0 Y$, were subcloned into pMP220 to form plasmids pBIO903 and pBIO917 (see Fig. 1). These two plasmids were mobilized into wildtype $A$. radiobacter ' 11305 ; for both, the transconjugants were mucoid. This provided further evidence that pBIO60 did not contain a gene that was functionally equivalent to exoX.

\section{ros regulates expression of exoY}

We had speculated (Aird $e t$ al., 1991) that the reason that certain exo alleles could be complemented by two different cosmids was that they were in a positively acting regulatory gene and so could be restored either by cloning that gene itself or by cloning the target structural gene such that it no longer needed the regulator. It subsequently transpired that the gene in one of the cosmids corresponded to ros, a known regulator (Brightwell et al., 1995), and here we have shown that the other cosmid, pBIO21, indeed contains a structural exo gene that encodes a glycosyltransferase.

To test if ros regulated expression of exoY, two exoY::pho $A$ mutant plasmids pBIO72 (containing the recessive exo Y2:: Tnpbo $A$ allele) and $\mathrm{pBIO} 92$ (containing the dominant exoY1:: Tnpbo $A$ allele) were transferred into the wild-type and each of the ros mutants Exo 81, Exo 53.1 and Exo 66 of $A$, radiobacter. These three mutants could all be complemented for EPS synthesis by both ros and $\operatorname{exo} Y$, but they differed in that Exo 81 accumulated large amounts of porphyrin and was EPS ${ }^{-}$on media with either glucose or succinate as $C$ source; in contrast, Exo 66.1 and Exo 53.1 were mucoid on the former medium. Cells were grown in minimal media and assayed for AP. As seen in Table 2, the levels of AP activity were consistently higher in the wild-type background than with any of these three mutants. There was a slight increase, though, even in Exo 81, when the fusion plasmids were present. This could be due to the fact that the defective $p b o A$ gene had been supplied with a ribosome-binding site and with the promoter of exo $Y$ expressed at a low basal level. These data suggest that transcription of exo $Y$ is normally activated by ros and that this is defective in the three mutants tested here. The data in Table 2 refer to the activities obtained with cells grown in normal media in which glycetol was the $C$ source. The assays were also done on these strains that had been grown with succinate as sole $C$ source and in media that were deficient in iron; the results were essentially the same as those presented in Table 2.

The Ros protein binds to specific regions preceding genes whose expression it represses. These sequences contain structures of dyad symmetry (D'Souza-Alt et al., 1993); no sequences similar to such ros boxes were found in the region upstream of exoY, nor, indeed in the whole of the sequenced region. There is an imperfect inverted repeat [AAAATCCCA;N9;TCAAAT'T'T'T] 392 bp upstream of the translational start of exo $Y$ but there is no experimental evidence to show whether the Ros protein binds directly to that sequence or, indeed to any other region $5^{\prime}$ of exoY.

\section{Identification of two genes, aldA and oat $A$, upstream of exor}

Upstream of exo $Y$ we identified three other genes, two of whose products had significant homology to those of other bacterial genes with known functions (see Fig. 1). One of these, termed ald $A$, showed homology (46\% identity) to a part of the Eschericbia coli aldehyde dehydrogenase $(\mathrm{ALDH})$ (see Heim \& Strehler, 1991). Interestingly, the N-terminal region of AldA of Agrobacterium also shows conserved sequences that correspond to the $\alpha$-helix-turn- $\alpha$-helix motif (Dodd \& Egan, 1990) representing the DNA-binding region of a range of prokaryotic transcriptional regulators, including Cro, Fnr, TrpR, PhoB and SinR. It seems possible that the Ald A protein of $A$. radiobacter may be a DNA-binding protein that also has an extensive motif resembling part of the E. coli ALDH enzyme. It is conceivable that this latter motif responds to molecules that resemble aldehydes, or their enzymic products, and that such an interaction may determine whether the regulatory protein actively induces (or represses) transcription of its target gene(s) (Tiburtius, 1995).

Transcribed divergently from ald $A$, and separated from it by $530 \mathrm{bp}$, is an ORF (2425-3214); the product of this ORF (termed oat $A$ ) had a striking and extensive similarity to a family of bacterial $\omega$-aminotransferases, the greatest being to pyruvate transaminase of $E$. coli; it was also similar to the product of the avrD gene of the phytopathogen Pseudomonas syringae (Kobayashi et al., 1990). Downstream of oat $A$ and transcribed in the same orientation was one other significant ORF (termed ORF A; Fig. 1). The deduced product of this ORF had no clear homology with any protein sequence in databases.

Unfortunately, the failure to conduct site-directed mutagenesis according to Ruvkun \& Ausubel (1981) in $A$. 
radiobacter (Aird et al., 1991) precluded us from determining the phenotypic effects of mutation in any of these genes.

\section{DISCUSSION}

In this paper we have shown that certain exo mutants of $A$. radiobacter can be complemented for their failure to make EPS by the cloned exoY gene. Close homologues of this gene have been identified in various Gram-negative and -positive bacteria; in all cases, mutations lead to a defect in the synthesis of the particular EPS that is characteristic of the particular genus.

Some of the mutants that were complemented for EPS synthesis by exoY were also complemented by the regulatory gene ros. We propose that these mutants are defective in ros, whereas those mutants that were complemented for EPS synthesis by exoY but not by ros are mutated in exoY itself. For the mutant strains Exo 81 and Exo 53.1, their defects in haem synthesis, indicated by the accumulation of protoporphyrin, were not complemented by exo $Y$, but have been shown to be complemented by ros (Brightwell et al., 1995). Taken together, we propose that ros acts as a positively acting transcriptional regulator for exo genes and for genes involved in haem biosynthesis. Thus, bona fide ros mutations can be complemented by ros for both phenotypes, whereas the cloned exo target gene can complement only the EPS defect. It is possible that the ros mutations in Exo 53.1 and in Exo 81 abolish the ability of the protein to recognize or activate the promoters at either the exo or the haem gene loci, whereas with Exo 66.1, the defective activation is confined to the recognition of the exo gene(s).

We now have direct evidence that ros acts positively on the expression of exo $Y$ of $A$. radiobacter. Since this was deduced from studies on the $e \times 0 Y:: \operatorname{Tn} p b o A$ fusions, we did not formally show that this regulation was at the level of transcription; the levels of AP activity measured here would be a function of the transcription, translation and 'targeting' of the ExoY:: PhoA fusion protein to the membrane. However, given the previously identified effects of ros on other genes (Brightwell et al., 1995; D'Souza-Alt et al., 1993; Cooley et al., 1991), it seems inherently likely that its effect on exoY expression is at the level of transcription. However, in previous studies, ros and the related R. meliloti gene mucR (Keller et al., 1995) had only been shown to act as repressors of transcription, not activators as is the case with its effect on exo $Y$. There are, though, many examples of bacterial DNA-binding transcriptional regulators acting positively at some promoters but negatively at others. It is also conceivable that ros might normally function as a repressor of a gene which, in turn, represses expression of exoY. Thus, mutations in ros would cause that repressor to be active and so depress the transcription of exoY.

The DNA sequence to which the Ros protein of $A$. tumefaciens binds and which includes a region of dyad symmetry known as the ros box has no precise counterpart in the region of DNA up to $3.2 \mathrm{~kb}$ upstream of $e x o Y$. If the Ros protein of $A$. radiobacter does bind to DNA upstream of exoY (something that has not been proven), it must therefore have alternative binding sites to the ros box. Certainly, even in A. tumefaciens, the sequence of dyad symmetry $5^{\prime}$ of $\operatorname{vir} C$ is inverted relative to that preceding ros, suggesting that there may be more than one sequence that is recognized by the Ros protein (D'SouzaAlt $e t$ al., 1993).

Three closely linked exo $Y:: \operatorname{Tn} p h o A$ mutant alleles were isolated and mapped precisely. All three expressed AP, indicating that the AP part of the fusion proteins was, in all cases, exposed to the periplasmic space. The fusion junctions were located in a region of the protein that contained charged residues, consistent with this region of the protein not being buried in the bacterial membrane, but rather being exposed to the periplasmic space.

Strikingly, one of these mutations caused a dominant phenotype whereas the other two were recessive. Other studies in Rbizobium had shown that such dominant phenotypes caused by mutations in exoY were due to the presence of the 'extra' copies of exoX on the same recombinant plasmid (Gray et al., 1990; Reed et al., 1991a). However, this does not appear to be the explanation for the phenomenon described here. By both sequence and functional analyses, there does not appear to be a gene cotresponding to exoX in the vicinity of exoY which is present in $\mathrm{pBIO} 60$. A tentative explanation for the observation points to a possibly trivial explanation. Since the three mutations studied here all express AP, they must all generate fusion proteins between part of ExoY and PhoA. It is likely that the various proteins that engage in EPS synthesis form complexes with each other at or near the bacterial membrane (see model by Leigh \& Walker, 1994). It is possible that if a fusion protein between one of these exo gene products is formed, depending on the exact position of the fusion, the mutant protein might be able to participate in the formation of the complex but, depending on the exact position and thus the spatial orientation of the AP part of the fusion protein, this may or may not prevent other proteins of the complex from functioning properly or, indeed from being able to participate in it at all. If, as is the case here, the fusion protein is encoded by a plasmid, it will be present in larger amounts since the vector for the cloned exoY::Tnpbo $A$ fusion has a copy number of approximately eight per cell (unpublished observations).

The precise interactions between proteins in the EPSforming complex may also explain another somewhat surprising result, namely the failure of the exoY genes of Rbizobium to correct exoY mutants of Agrobacterium and vice versa (Aird et al., 1991), despite the near-identity of the EPSs that are made by the two genera and the $>80 \%$ identity of the amino acid sequence of the two ExoY proteins. It seems reasonable to suggest that although the ExoY proteins of these two genera may carry out exactly the same catalytic functions (i.e. the initial glycosylation step), because they each act as part of a protein complex, the heterologous combination in which the ExoY protein of one of the genera is required to act in the context of the Exo proteins of the other genus does not result in a functional complex. 
Future work is designed to understand better the regulatory function of ros. It has been shown to be a repressor and, here, also to have activating abilities. The ros and $m u c R$ genes encode a new class of bacterial regulators with no sequence similarities to any other DNA-binding regulatory proteins, although Cooley et al. (1993) suggested that the Ros protein contains a motif with some similarity to a zinc-finger. We wish to know in more detail how it activates expression of exo $Y$ and how it is involved, apparently, in the biosynthesis of haem in Agrobacterium.

\section{ACKNOWLEDGEMENTS}

We are very grateful to Alan Cavill for skilled technical assistance and to Richatd James for the synthesis of the sequencing primers. This work was funded in part by the BBSRC of the UK.

\section{REFERENCES}

Aird, E. L. H., Brightwell, G., Jones, M. A. \& Johnston, A. W. B. (1991). Identification of the exo loci requited for cxopolysaccharide synthesis in Agrobacteritm radiobacter NCIB 11883. I Gen Microbiol 137, 2287-2297.

Becker, A., Kleikmann, A., Arnold, W. \& Puhler, A. (1993a). Analysis of the Rbizabium melilati axoH-exoK-exoL fragment; ExoK shows homology to excreted $\beta-1,3 \rightarrow 1,4$-glucanases and ExoH resembles membrane proteins. Wol Gen Genet 238, 145-154.

Becker, A., Kleikmann, A., Arnold, W. \& Puhler, A. (1993b). Identification and analysis of the Rhizobium meliloti exo.AMONP genes involved in exopolysaccharide biosynthesis and mapping of promoters located on the exolIKLAMONP fragment. Mol Gen Genet 241, 367-379.

Becker, A., Kleickmann, A., Kuster, H., Keller, M., Arnold, W. \& Puhler, A. (1993c). Analysis of the Rbizobium meliloti genes exoV, exolW, exoT, and exol involved in the exopolysaccharide biosynthesis and nodule invasion; exoV and exoW probably encode glycosyltransferases. Mol Plant-Microbe Interact 6, 735-744.

Borthakur, D. \& Johnston, A. W. B. (1987). Sequence of psi, a gene on the symbiotic plasmid which inhibits exopolysaccharide production and demonstration that its transcription is inhibited by psr, another gene on the sym plasmid. Mol Gen Genet 207, 149-154.

Borthakur, D., Downie, J. A., Johnston, A. W. B. \& Lamb, J. W. (1985). psi, a plasmid-linked Rbizobitm phaseoli gene which inhibits exopolysaccharide production and is required for symbiotic nitrogen fixation. Mol Gen Genet 200, 278-282.

Borthakur, D., Barker, R. F., Latchford, J. W., Rossen, L. \& Johnston, A.W. B. (1988). Analysis of pss genes of Rhizobium leguminasarum required for exopolysaccharide synthesis and nodulation of peas: their primary structure and their interaction with $p s i$ and other nodulation genes. Mol Gen Genet 213, 155-162.

Brickman, E. \& Beckwith, J. (1975). Analysis of the regulation of Escbericbia coli alkaline phosphatase synthesis using deletions and $\phi 80$ transducing phages. $J$ Bacteriol 119, 307-316.

Brightwell, G., Hussain, H., Tiburtius, A., Yeoman, K. H. \& Johnston, A. W. B. (1995). Pleiotropic effects of regulatory ros mutants of Agrobacterium radiabacter and their interaction with $\mathrm{Fe}$ and glucose. Mol Plant-Microbe Interact 8, 747-754.

Buendia, A. M., Enenkel, B., Koplin, R., Niehaus, K., Arnold, W. \& Puhler, A. (1991). The Rbizobium meliloti exoZ/exoB fragment of megaplasmid 2: ExoB functions as a UDP-glucose 4' epimerase and Exo' shows homology to $\operatorname{NodX}$ of $R$. leguminosarum bv. viciae strain TOM. Mol Microbiol 5, 1519-1530.
Cangelosi, G. A., Hung, L., Puvanesarajah, V., Stacey, G., Ozga, D. A., Leigh, J. A. \& Nester, E. W. (1987). Common loci for Agrobacterium tumefaciens and Rbizobium meliloti exopolysaccharide synthesis and their roles in plant interactions. I Bacteriol 169, 20862091

Close, T. J., Tait, R. C. \& Kado, C. I. (1985). Regulation of Ti plasmid virulence genes by a chromosomal locus of Agrobaterium tumefaciens. J Bacteriol 164, 774781.

Cooley, M. B., D'Souza, M. R. \& Kado, C. I. (1991). The vir $C$ and virD operons of Agrabacterium Ti plasmid are regulated by the chromosomal ras gene; analysis of the cloned ros gene. J Batteriol $173,2608-2616$.

Derman, A. I. \& Beckwith, J. (1995). Escherichia coli alkalinc phosphatase localized to the cytoplasm slowly acquires enzymatic activity in cells whose grow th has been suspended: a caution for gene fusion studies. J Bacteriol 177, 3764-3770.

Dodd, I. B. \& Egan, J. B. (1990). Improved detection of helix-turnhelix DNA binding motifs in protein sequences. Nucleic Acids Res 18, 5019-5026.

Doherty, D., Leigh, J. A., Glazebrook, J. \& Walker, G. W. (1988). Rhizobium meliloti mutants that overproduce the $R$. meliloti acidic calcofuor-binding exopolysaccharide. J Bacteriol 170, 4249-4256.

D'Souza-Alt, M. R., Cooley, M. B. \& Kado, C. I. (1993). A nalysis of the Ros repressor of the $\operatorname{vir} C$ and $\operatorname{vir} D$ operons: molecular intercommunication between plasmid and chromosomal genes. I Butterial 175, 34863490.

Figurski, D. H. \& Helinski, D. R. (1979). Replication of an origincontaining derivative of plasmid RK2 dependent on a plasmid function provided in trans. Proc Natl Acad Sci US A 76, 1648-1652.

Finan, T. M., Kunkel, B., De Vos, G. F. \& Signer, E. R. (1986). Second symbiotic megaplasmid in Rhizobium meliloti carrying exopolysaccharide and thiamine synthesis genes. / Bacteriol 165, $66-72$.

Friedman, A. M., Long, S. R., Brown, S. E., Buikema, W. J. \& Ausubel, F. M. (1982). Construction of a broad host-range cosmid cloning vecror and its use in generic analysis of Rbizobium mutants. Gene 18, 289-296.

Glazebrook, J. \& Walker, G. C. (1989). A novel exopolysaccharide can function in the place of the calcofluor-binding exopolysaccharide in nodulation of alfalfa by Rizizobium meliloti. Cell 56, $661-672$.

Gray, J. X., Djordjevic, N. A. \& Rolfe, B. G. (1990). Two genes that regulate exopolysaccharide production in Rbizobium sp. NGR234. J Bacteriol 172, 193-203.

Heim, R. \& Strehler, E. E. (1991). Cloning an Escherichia coli gene encoding a protein remarkably similar to mammalian aldehyde dehydrogenases. Gene 99, 15-23.

Jiang, X.-M., Neal, B., Santiago, F., Lee, S. J., Romana, L. K. \& Reeves, P. R. (1991). Structure and sequence of the $r f b$ (O-antigen) gene cluster of Salmonella serovar typhimurium (strain LT2). Mol Microbiol 5, 695-713.

Keller, M., Roxlau, A., Weng, W. M., Schmidt, M., Quandt, J., Niehaus, K., Jording, D., Arnold, W. \& Puhler, A. (1995). Molecular analysis of the Rbizobium meliboti muc $R$ gene regulating the biosynthesis of the exopolysaccharides succinoglycan and galactoglucan. Mol Plant-Microbe Interact 8, 267-277.

Kobayashi, D. Y., Tamaki, S. J. \& Keen, N. T. (1993). Molecular characterisation of a virulence gene $\mathrm{D}$ in Pseudomonas syringae pathovar tomato. Mol Plant-Microbe Interact 3, 94-102.

Kyte, J. \& Doolittle, R. F. (1982). A simple method for displaying the hydropathic character of a protein. J Mol Biol 157, 105-132.

Latchford, J. W., Borthakur, D. \& Johnston, A. W. B. (1991). The 
products of Rhizobium genes, psi and pss, which affect exopolysaccharide production, are associated with the bacterial cell surface. Mol Microbiol 5, 2107-2114.

Leigh, J. A. \& Coplin, D. L. (1992). Exopolysaccharides in plantbacterial interactions. Annu Rev Microbiol 46, 307-346.

Leigh, J. A. \& Walker, G. C. (1994). Exopolysaccharides of Rhizobitm: synthesis, regulation and symbiotic function. Trends Genet $10,63-67$.

Long, S., McCune, S. \& Walker, G. C. (1988). Symbiotic loci of Rhizobium meliloti identified by random Tnpho $A$ mutagenesis. I Bacteriol 170, 4257-4265.

Manoil, C. \& Beckwith, J. (1985). Tnpho $A$ : a transposon probe for protein export signals. Proc Natl Acad Sci US A 82, 8129-8137.

Messing, J., Crea, R. \& Seeburg, P. H. (1983). A system for shotgun DNA sequencing. Nuleic Acids Res 9, 309-314.

Pabo, C. O. \& Sauer, R. T. (1984). Protein-DNA recognition. Annu Rev Biocbem 35, 293-321.

Prinz, W. A. \& Beckwith, J. (1994). Gene fusion analysis of membrane protein topology: a direct comparison of alkaline phosphatase and $\beta$-lactamase fusions. $J$ Bacteriol 176, 6410-6413.

Reed, J. W., Capage, M. \& Walker, G. C. (1991a). Rbizobium meliloti $e \times 0 G$ and exoJ mutations affect the ExoX-ExoY system for modulation of exopolysaccharide production. I Bacteriol 173, 3776-3788.

Reed, J. W., Glazebrook, J. \& Walker, G. C. (1991b). The exoR gene of Rbirobium meliloti affects RNA levels of other exo genes but lacks homology to known transcriptional regulators. J Bacteriol 173, 3789-3794.

Reuber, T. L. \& Walker, G. C. (1993). Biosynthesis of succinoglycan, a symbiotically important exopolysaccharide of Rbizobium meliloti. Cell 74, 269-280.

Reuber, T. L., Long, S. \& Walker, G. C. (1991). Regulation of Rhizobium meliloti exo genes in free-living cells and in plants examined by using Tnpho $A$ fusions. $J$ Bacteriol 173, 426-434.

Rossen, L., Johnston, A. W. B. \& Downie, J. A. (1984). DNA sequence of the Rhizobium leguminosarum nodulation genes nod $A, B$ and $C$ required for root hair curling. Nucleic Acids Res 12, 9497-9508.

Rubens, C. E., Heggen, I. M., Haft, R. F. \& Wessels, M. R. (1993). Identification of $c p s D$, a gene essential for type-III capsule expression in group-B Streptococci. Mol Microbiol 8, 843-855.

Ruvkun, G. \& Ausubel, F. M. (1981). A general method for sitedirected mutagenesis in prokaryotes. Nature 289, 85-88.

Sambrook, J., Fritsch, E. F. \& Maniatis, T. (1989). Molecular Cloning: a Laboratory Manual, 2nd edn. Cold Spring Harbor, NY: Cold Spring Harbor Laboratory.

Spaink, H. P., Okker, R. J. H., Wijffelman, C. A., Pees, E. \& Lugtenberg, B. J. J. (1987). Promoters in the nodulation region of the Rbizobium leguminosarum Sym plasmid pRL1 JI. Plant Mol Biol 9, $27-39$.

Sutherland, I. W. (1985). Biosynthesis and composition of Gramnegative bacterial extracellular and wall polysaccharides. Annu Rev Microbial 39, 243-270.

Tiburtius, A. (1995). Molecular genetics of genes involved in exopolysaccharide synthesis in Agrobacterium radiobacter. $\mathrm{PhD}$ thesis, University of East Anglia.

Vanderslice, R. W., Doherty, D. H., Capage, H. A., Betlach, M. R., Hassler, R. A., Henderson, N. M., Ryan-Graniero, J. \& Techlenburg, M. (1989). Genetic engineering of polysaccharide in Xanthomonas campestris, pp. 145-156. In Recent Developments in Industrial Polysaccharides: Biomedical and Biotechnological Advances, vol. 5. Edited by I. C. M. Creszenzi \& S. S. Stivola. New York: Gordon \& Breach Science.

Vieira, J. \& Messing, J. (1984). Production of single-stranded plasmid DNA. Methods Enymol 153, 3-11.

Wood, W. B. (1966). Host specificity of DNA produced by Eschericbia coli bacterial mutations affecting the restriction and modification of DNA. J Mol Biol 16, 118-133.

Received 1 February 1996; revised 18 April 1996; accepted 15 May 1996. 